ERRATUM

G. Bain · F.C. Mansergh $\cdot$ M.A. Wride $\cdot$ J.E. Hance

A. Isogawa $\cdot$ S.L. Rancourt $\cdot$ W.J. Ray $\cdot$ Y. Yoshimura

T. Tsuzuki $\cdot$ D.I. Gottlieb $\cdot$ D.E. Rancourt

\title{
ES cell neural differentiation reveals a substantial number of novel ESTs
}

Published online: 19 October 2000

(C) Springer-Verlag 2000

\section{Funct Integr Genomics (2000) DOI $10.1007 / \mathrm{s} 101420000014$}

Due to an unfortunate oversight, the captions for Fig. 1 and Fig. 2 were reversed.

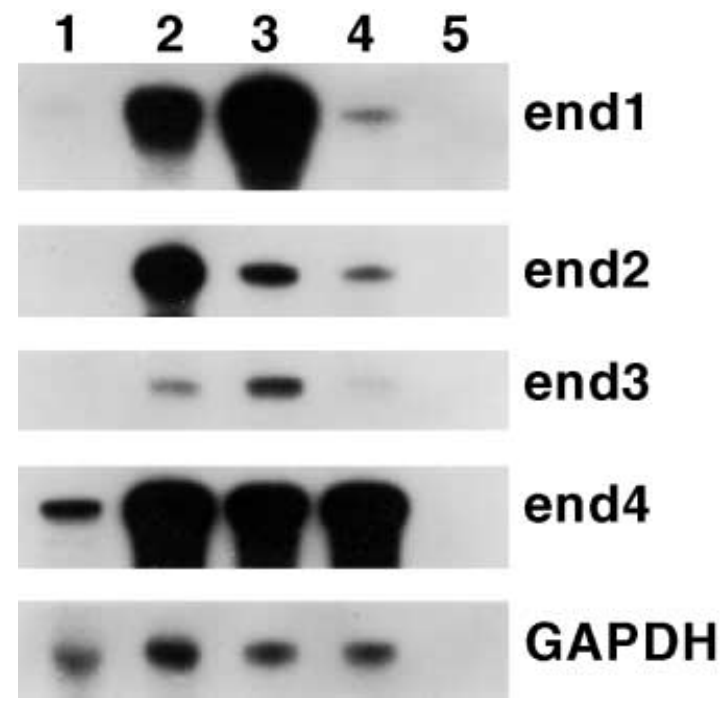

Fig. 1 Expression of endl-4 genes in ES cells and in mouse brain. RNase protection assays demonstrate that the endl-4 genes are expressed at low or undetectable levels in undifferentiated ES cells (lane 1). All four genes are expressed at moderate to high levels in ES cells undergoing the early stages of neural differentiation in vitro (lane 2). Furthermore, all of these genes are expressed in RNA prepared from embryonic day 16.5 (lane 3) or adult (lane 4) mouse brain. Yeast tRNA (lane 5) was included as a negative control, and a GAPDH probe was used to ensure that equivalent amounts of RNA were assayed

G. Bain · F.C. Mansergh - M.A. Wride - J.E. Hance · S.L. Rancourt D.E. Rancourt

Department of Biochemistry and Molecular Biology,

The University of Calgary, 3330 Hospital Drive NW,

Calgary, Alberta, Canada, T2N 4N1

G. Bain · W.J. Ray · D.I. Gottlieb

Department of Anatomy and Neurobiology,

Washington University School of Medicine,

660 South Euclid Ave, St. Louis, MO 63110, USA

A. Isogawa $\cdot$ Y. Yoshimura $\cdot$ T. Tsuzuki

Department of Medical Biophysics and Radiation Biology,

Graduate School of Medical Sciences, Kyushu University,

1-1, Maidashi 3-Chome, Higashi-Ku, Fukuoka, 812-8582, Japan

Present address:

G. Bain, AVENTIS Pharmaceuticals Inc., 26 Landsdowne Street, Cambridge, MA 02139-4234, USA 


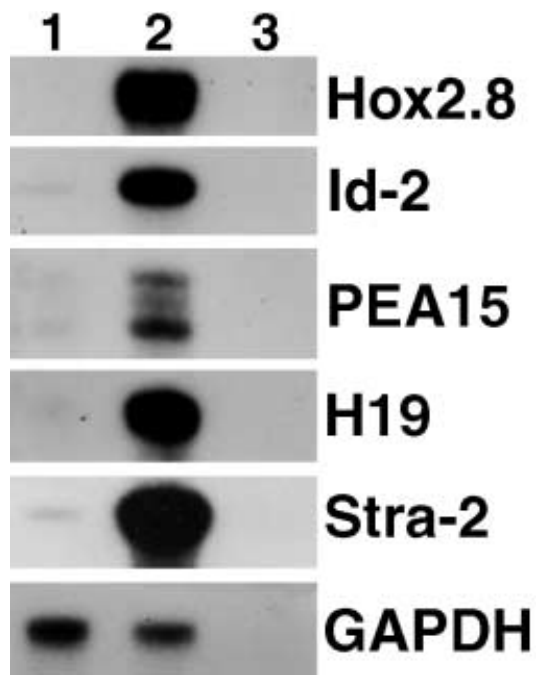

Fig. 2 Expression of several known genes is upregulated in embryonic stem (ES) cells undergoing neural differentiation in culture. Sequence analysis of cDNA clones isolated from our subtractive hybridization screen revealed several known genes, including Hox2.8, Id2, PEA15, H19, and Stra2. RNase protection assay analysis of these genes indicates that all of them are expressed at low or undetectable levels in RNA prepared from undifferentiated ES cells (lane 1) but then are strongly upregulated in ES cells undergoing the early stages of neural differentiation in culture (lane 2). Yeast tRNA was included as a negative control (lane 3). A GAPDH probe was used to confirm that equivalent amounts of RNA were assayed 